\title{
Personality traits and gross motor performance in children from Muzambinho/MG
}

\author{
CÁSSIO M. MEIRA JR. ${ }^{1 \mid}$ ANA C. GOMES ${ }^{1}$ | FÁBIO R. F. GOMES ${ }^{1}$ | SUZIANE P. SANTOS 2 | LUCIANO BASSO | GO \\ $\mathrm{TANI}^{3}$ |
}

1University of São Paulo. São Paulo, Brazil, School of Arts, Sciences, and Humanities, São Paulo, SP, Brazil.

2Federal University of Triângulo Mineiro. Department of Sport Sciences, Uberaba, MG, Brazil.

3University of São Paulo. São Paulo, Brazil, School of Physical Education and Sport, São Paulo, SP, Brazil.

Correspondence to: Cassio M. Meira Jr., EACH-USP, Av. Arlindo Bettio 1000, São Paulo/SP, 03828-000.

email: cmj@usp.br

https://doi.org/10.20338/bjmb.v13i4.140

\begin{abstract}
HIGHLIGHTS
- There are no significant associations between scores of personality traits and gross motor performance in children from Muzambinho/MG.

- Two thirds of the sample $(n=190)$ showed poor or very poor levels of gross motor development.

- The motor quotient (locomotion and object control) of the sample was below Percentile according to TGMD-2 normative scores.

- The sample exhibited low levels of Psychoticism, average levels of Neuroticism, and high levels of Extraversion/Introversion and Sociability.

\section{ABBREVIATIONS \\ ETPC Escala dos Traços de Personalidade para Crianças \\ IBGE Instituto Brasileiro de Geografia e Estatística \\ PTSC Personality Trait Scale for Children \\ TGMD-2 Test of Gross Motor Development}

BACKGROUND: Stable personality features might differentiate children while performing gross motor skills. AIM: (1) to report the scores of four personality traits (Extraversion/Introversion, Neuroticism, Psychoticism, and Sociability) and gross motor performance, (2) to describe the frequency of children in each level of gross motor development, (3) to investigate relationships between personality trait scores and gross motor performance scores.

METHOD: 190 scholars (6-12 years old) voluntarily answered the Personality Trait Scale for Children (PTSC) and took part in the Test of Gross Motor Development (TGMD-2, Ulrich, 2000), performing six locomotor and six object control skill tests.

RESULTS: (1) Low levels of Psychoticism, average levels of Neuroticism, and high levels of Extraversion/Introversion and Sociability were identified. (2) The motor quotient (composed of the subscales locomotion and object control) of the sample was positioned below Percentile 50 and two-thirds of the children were located in the poor/very poor level of gross motor development. (3) Correlations were extremely low between personality traits and motor variables, which prevents any prediction.

CONCLUSION: Personality traits are not associated with gross motor performance in children from Muzambinho/MG. The low level of gross motor development should be considered in public policies and physical activity interventions for children with similar characteristics to our sample.

\section{INTRODUCTION}

Motor development is characterized by constant shifts in patterns of movement that allow physical and motor progress, both from a quantitative (greater number of movements) and qualitative (greater complexity of movements) perspective ${ }^{1}$. The emergence and maturation of movements occur through reorganization processes of basic movements (running, jumping, throwing) into increasingly complex ones so that the child acquires a wide range of combined movements for future application in specific situations ${ }^{2,3}$. The TGMD-2 focus is on gross motor skills regarding object control and locomotion oriented to a goal and involving large, force-producing muscles of the trunk, arms, and legs ${ }^{4}$. One of the main tests to investigate gross motor performance in children is the TGMD-24, a well-constructed and standardized test including locomotor and object control skills. The TGMD-2 was designed to evaluate motor performance associated with

\begin{tabular}{l|l|l|l|l}
\hline Meira Jr. et al. & 2019 & VOL.13 & N.4 & https://doi.org/10.20338/bjmb.v13i4.140
\end{tabular}


changes in motor development, and is a means of screening the level of motor performance in childhood to prevent lifelong problems with motor skills and self-concept ${ }^{4}$. There is evidence that supports the association of self-concept with personality traits ${ }^{5,6}$.

Personality has been shown to be the main field of investigation of individual differences in the motor domain 7 . Due to their relatively stable and long-lasting characteristics, personality traits are predispositions that describe personality profiles of an individual across time and contexts. Eysenck's personality model 8 advocates that personality is formed by traits, which have mostly been attributed to genetic inheritance ${ }^{7,8}$. The effects of these personality predispositions on behavioral patterns have been reported in motor performance as a potential tool for individualizing instruction as well as for selecting people who are more prone to perform specific functions or tasks $8,9,10,11$. There are questionnaires to measure personality traits, which show positive and significant correlations with direct (cortical activation level) and indirect (electrical conductance of the skin) psychological and physiological measurements of personality ${ }^{8}$. Personality questionnaires enable researchers to classify an individual, for example, in the trait of extraversion/introversion, high scores describe a typical extravert, low scores a typical introvert, and intermediate scores portray an ambivert.

Psychoticism refers to tough-mindedness, aggressiveness, and egocentrism with high scores implying individualism, impulsivity, and loneliness. Neuroticism, in turn, is associated with emotional instability such that high scores indicate that individuals tend to have significant levels of anxiety, hostility, and vulnerability. Extraversion/introversion entails characteristics of vivacity, creativity, and the search for sensations in such a way that an introverted person (low scores) predisposes her/himself to being quiet and reserved, while an extraverted person (high scores) tends to be sociable, seek stimuli, and take risks. Sociability is related to the tendency to behave within social rules and conveniences so that lower scores signify some independence from social norms (even behaving antisocially), while high scores predispose the individual to behave within the limits of desirable rules $8,10,12$. Differences in personality traits have been explained by cortical levels. Extraverts are distinguished from introverts because of their different basal levels of cortical activation. Introverts exhibit higher levels and, consequently, try to avoid stimuli, whereas extraverts are known as stimuli-hunters due to their low cortical activation ${ }^{13,14}$.

Studies have determined relationships between personality traits and motor behavior in adults $9,10,13,14,15$ and children $11,16,17,18$. However, the studies conducted with children were limited by small samples and the scrutiny of only one personality trait of interest ${ }^{16,17,18}$. In this vein, we believe that more thorough investigation is needed, employing a large sample and focusing not only on one trait but on a set of personality traits. Thus, our objectives were threefold: (1) to report the scores of (a) four personality traits (Extroversion/Introversion, Neuroticism, Psychoticism, and Sociability) and (b) gross motor performance (locomotion, object control, and motor quotient); (2) to describe the frequency of children in each normative range of gross motor performance; (3) to investigate relationships between personality trait scores and gross motor performance scores. The hypothesis of objective 1 was that personality trait scores and motor performance scores would be similar to other Brazilian samples. The hypothesis of objective 2 was that the majority of children would fall into or above average normative ranges (average and above average). Regarding the third objective we expected that there would be (a) direct and high magnitude correlations between Extraversion/Introversion and 
Sociability scores and gross motor coordination scores and (b) inverse and high magnitude correlations between Neuroticism and Psychoticism scores and gross motor coordination scores - as a result of these hypotheses, personality traits would predict gross motor coordination.

\section{METHODS}

\section{Participants}

A total of 190 students from 6 to 12 years of age (average of $7.8 \pm 1.2$ years), from five public schools in Muzambinho/MG participated in this study. The stratification by age group was distributed as follows: 11 girls and 16 boys of 6 years of age, 32 girls and 25 boys of 7 years of age, 32 girls and 31 boys of 8 years of age, 15 girls and 15 boys of 9 years of age, three children of each sex in the 10-year age group, two girls and three boys in the 11-year age group, and two 12-year-old boys. The research was approved by the Research Ethics Committee under $n^{0} 13832$. The children and their parents/guardians formally consented to participate in the study by signing a consent form which assured confidentiality and anonymity. The inclusion criterion was the child's desire to participate and the exclusion criterion was the existence of any physical issue that prevented the child from moving. This work is part of a longitudinal study - for details see Basso et al. ${ }^{17}$. The parents completed the Brazilian Economic Classification Criteria questionnaire from the Instituto Brasileiro de Geografia e Estatística (IBGE) which showed that $90 \%$ of the sample belonged to economic classifications $C$ and $D$ (where $A 1, A 2, B 1$, and $B 2$ are above and $E$ is below these classifications). We also scrutinized physical activity levels via a questionnaire ${ }^{19}$ and the responses indicated similar levels of mild (minimal effort), moderate (not exhausting), and total (mild+moderate+strenuous in a week) physical activity; the boys reported slightly higher levels of strenuous (heart beats rapidly) physical activity than the girls; 7-year-old children of both sexes reported lower levels of strenuous physical activity. The sample demonstrated average levels of total weekly physical activity and, in general, younger boys and older girls self-declared lower values, indicating that there is no significant change in total physical activity across ages for either sex.

\section{Instruments, design and procedure}

Individually and in a quiet room the children answered the Personality Trait Scale for Children (PTSC) (in Portuguese: Escala dos Traços de Personalidade para Crianças ETPC), a valid instrument to measure personality traits in Brazilian children (12). When necessary, the researchers helped the children to answer the questions, clarifying the meaning of difficult words, generally by verbalizing synonyms. The PTSC evaluates traits of Extraversion/Introversion (0-10), Neuroticism (0-7), Psychoticism (0-11), and Sociability $(0-6)$. The answers to the 30 questions are in the form of 'yes' or 'no'. A sample of questions is as follows: 1- Do you like to make a joke that bothers another person? 2Would you like to know that other children are afraid of you? 3- Are you joyful and fun? 4Do you sometimes feel sad without knowing why? 5- Do you sometimes like to make animals feel mad?

Gross motor performance was evaluated by the Test of Gross Movement Development (TGMD-2) ${ }^{4}$, consisting of six locomotor (run, gallop, hop, leap, horizontal jump, and slide) and six object control (striking a stationary ball, stationary dribble, catch, 
kick, overhand throw, and underhand roll) skills. Test protocol and performance criteria were applied in accordance with the TGMD-2 examiner's manual. For each skill, one researcher demonstrated each movement once before the child performed a familiarization trial followed by two main trials. The trials were filmed and analyzed in slow motion using Kinovea software. These two trials were considered for analyses: if the child performed a skill component, the observer marked ' 1 ' and if the child did not perform the component the observer marked ' 0 '. The observers agreed on at least $90 \%$ of all skills, representing reasonable intraobserver and interobserver reliability ${ }^{10}$. The examiner completed this procedure for each of the two trials and then worked out the total score. The scores of each skill were added to the subtest scores (locomotion and object control) which, in turn, were converted into a standard score that was finally combined and converted into the Gross Motor Quotient. Calculation steps were performed in the following order: 1) the total score of the two main trials of each skill for each movement class = gross score of locomotion and object control subtests; 2) decoding of each gross score in percentiles according to the norm for sex and age = percentile for each subtest; 3 ) total of the percentiles; 4) decoding of the motor quotient scale. For methodological details of TGMD-2 analysis, see previous studies carried out in Muzambinho/MG ${ }^{18,20}$.

\section{Data analysis}

Data related to objectives 1 and 2 were analyzed by means of exploratory and descriptive statistical techniques for each variable.

Data of the third objective were analyzed through associations between variables in the form of interclass correlations, a statistical technique used to determine the relationship between two or more interval or discrete variables.

For all analyses, significant levels were set at 5\%. We used Microsoft Excel for data registration, organization, and tabulation, and SPSS version 24 (IBM) for statistical analyses.

\section{RESULTS}

\section{Scores on personality traits}

The mean value of Extraversion/Introversion was 6.95, with a standard deviation of 1.49 (from 0 to 10); the majority, 124 children (65.3\%), received scores above average and $66(34.7 \%)$ below average. Concerning Neuroticism, the mean was 3.85 and the standard deviation 1.71, with a range from 0 to 7 ; there were 112 children $(59.9 \%)$ above and $78(41.1 \%)$ below average. The children scored a mean of 2.80 in Psychoticism with a standard deviation of 2.02 (range 0 to 9); 102 children (53.7\%) were below and $88(46.3 \%)$ above average. Regarding Sociability, the mean was 3.72 and the standard deviation 1.73 (range 0 to 6$) ; 108$ children (56.8\%) were above and 82 children (43.2\%) below average (Table 1).

Table 1 - Means \pm standard deviations of personality traits

\begin{tabular}{cccc}
\hline $\begin{array}{c}\text { Extraversion/Introversion } \\
(0-10)\end{array}$ & $\begin{array}{c}\text { Neuroticism } \\
(0-7)\end{array}$ & $\begin{array}{c}\text { Psychoticism } \\
(0-9)\end{array}$ & $\begin{array}{c}\text { Sociability } \\
(0-6)\end{array}$ \\
\hline $6.95 \pm 1.49$ & $3.85 \pm 1.71$ & $2.80 \pm 2.02$ & $3.72 \pm 1.73$ \\
\hline
\end{tabular}




\section{Motor performance scores}

Raw scores on each subscale were converted to standard scores which ranged from 1 to 20. For the locomotion subscale, the mean value was 5.27 and the standard deviation 1.43. With respect to the object control subscale, the mean was 7.21 with a standard deviation 2.29 (Table 2).

The mean value of the motor quotient (ranging from 46 to 120) was 77.42 with a standard deviation of 8.66 ; 102 children (53.7\%) were below, while 88 (46.3\%) were above average (Table 2).

\begin{tabular}{ccc}
\multicolumn{3}{c}{ Table 2 - Means \pm standard deviations of locomotion scores and object control } \\
\hline \begin{tabular}{ccc} 
Locomotion (1-20) & $\begin{array}{c}\text { Object Control } \\
(1-20)\end{array}$ & $\begin{array}{c}\text { Motor Quotient } \\
(46-120)\end{array}$ \\
\hline $5.27 \pm 1.43$ & $7.21 \pm 2.29$ & $77.42 \pm 8.66^{*}$ \\
\hline$* 102(53.7 \%)$ below average; $88(46.3 \%)$ above average
\end{tabular}
\end{tabular}

\section{Frequency of children in levels of gross motor development}

According to the normative ranges proposed by the TGMD-2 test manual for the level of gross motor development, 17 children (9\%) were above average, $50(26.3 \%)$ on average, $70(36.8 \%)$ below average with a poor level, and $53(27.9 \%)$ below average with a very poor level. The majority of children (64.7\%) exhibited levels which were below average, that is, poor or very poor, while less than $10 \%$ of participants scored above average. This pattern points to a strong tendency towards low levels of gross motor development (Table 3).

Table 3 - Frequencies of children in each TGMD-2 normative range

\begin{tabular}{cccc}
\hline Above Average & Average & Poor & Very Poor \\
\hline $17(9 \%)$ & $50(26.3 \%)$ & $70(36.8 \%)$ & $53(27.9 \%)$ \\
\hline
\end{tabular}

\section{Associations between scores of personality traits and gross motor performance}

The exploratory analysis indicated an absence of extreme outlier values. The Kolmogorov-Smirnov distribution normality test with significance correction of Lilliefors indicated test values lower than 0.0001 in all the variables of interest: Extraversion/Introversion (0.167), Neuroticism (0.160), Psychoticism (0.192), Sociability (0.148), Locomotion (0.164), Object Control (0.120), and Motor Quotient (0.116). The most appropriate correlation technique for this violation of normal distribution of values, without data transformation, is Spearman's nonparametric correlation.

The Spearman's correlation matrix between personality trait and motor performance scores can be visualized in Table 4. Significant correlations were identified only within traits (negative between Neuroticism and Sociability and between Psychoticism and Sociability, positive between Neuroticism and Extraversion/Introversion) and within gross motor performance variables (all positive: Locomotion and Object Control, Locomotion and Motor Quotient, and Object Control and Motor Quotient). 
No significant correlations were detected between personality traits and motor performance scores; hence it was not necessary to proceed with a regression analysis in order to establish presumed causal relations among indicators (TGMD-2 and personality traits).

Table 4 - Spearman's correlation matrix between personality traits and gross motor performance

\begin{tabular}{cccccccc}
\hline & $\begin{array}{c}\text { Neuro- } \\
\text { ticism }\end{array}$ & $\begin{array}{c}\text { Socia- } \\
\text { bility }\end{array}$ & $\begin{array}{c}\text { Psycho- } \\
\text { ticism }\end{array}$ & $\begin{array}{c}\text { Extra- } \\
\text { version }\end{array}$ & $\begin{array}{c}\text { Loco- } \\
\text { motion }\end{array}$ & $\begin{array}{c}\text { Object } \\
\text { Control }\end{array}$ & $\begin{array}{c}\text { Motor } \\
\text { Quotient }\end{array}$ \\
\hline Neuroticism & - & - & - & - & - & - & - \\
Sociability & $0.275^{* *}$ & - & - & - & - & - & - \\
Psychoticism & 0.044 & $0.471^{* *}$ & - & - & - & - & - \\
Extraversion & $0.180^{*}$ & -0.094 & 0.110 & - & - & - & - \\
Locomotion & -0.058 & -0.012 & 0.029 & -0.024 & - & - & - \\
Object Control & 0.061 & 0.003 & -0.030 & 0.024 & $0.157^{*}$ & - & - \\
Motor Quotient & 0.015 & -0.013 & -0.015 & -0.013 & $0.595^{* *}$ & $0.870^{* *}$ & - \\
\hline
\end{tabular}

${ }^{*} p<0.05 ;{ }^{* *} p<0.01$.

\section{DISCUSSION}

The first objective of the present study was to report personality traits and motor performance scores. As expected, these values were similar to other Brazilian samples from Recife/PE ${ }^{16,17}$ and São Paulo/SP11. High scores were observed in Extraversion/Introversion and Sociability (60\%-70\% of the maximum score), low scores in Psychoticism (below $30 \%$ of the maximum score), and average scores in Neuroticism (50\%-60\% of the maximum score). Regarding TGMD-2 standardized motor performance values, our sample scored below average on both locomotion and object control subscales and on motor quotient. This pattern corroborates similar Brazilian studies conducted in Recife/PE ${ }^{16,17}$ and Muzambinho/MG ${ }^{18}$.

We also aimed to describe the frequency of children in each normative range of gross motor performance. Our expectation was that the frequency of children would be higher in the upper normative bands, that is, average and above average. This hypothesis was refuted since the results demonstrated that the majority of the children were classified as having poor and very poor motor development. Other studies with Brazilian children found similar results $2,3,17,18,20$. One of the possible reasons for this undesirable gross motor behavior could be the low levels of physical activity; however, additional data from the children on physical activity levels (see Participants in the Method section) showed that the average level of total (weekly) physical activity is satisfactory. This lack of association between motor performance and level of physical activity in Brazilian children has also been detected in a previous study ${ }^{16}$. It is possible that the poor motor performance of our sample is due to the nature of the skills test. Although the TGMD-2 was conceived and 
developed 4 employing prevailing motor skills from baseball, softball, and football (from the United States of America), even in societies where such sports are not popular (Brazil, for instance), more satisfactory gross motor performance was expected, with at least the majority of the children gaining average scores. Apart from striking a stationary ball, which is not a popular practice in Brazilian children's daily life, the TGMD-2 skills should be familiar to schoolchildren from six to twelve years of age, whether in formal or informal settings. Even though children are potentially capable of acquiring proficient developmental patterns in the studied age groups, there appears to be evidence that they are not reaching these standards at the end of the fundamental movement phase ${ }^{3,21}$. In addition, the lack of practice opportunities and the involvement of children with drugs might drive out motor development 22 . Thus, it seems important that additional opportunities for practice be given to children for them to acquire and refine motor skills throughout their motor development process. In this context, physical education at school is one of the scenarios where children can experience motor activities that provide a skill-based background for a healthy lifetime 1,23 .

Another aim of the present study was to investigate relationships between scores of personality traits and gross motor performance. As movement is associated with concepts of vitality, expansiveness, energy, and social acceptance, our expectation was that there would be (a) direct and high magnitude correlations between Extraversion/Introversion and Sociability scores and gross motor performance scores and (b) inverse and high magnitude correlations between Neuroticism and Psychoticism scores and gross motor performance scores. Accordingly, personality traits would be predictors of gross motor performance. Instead, our findings indicated extremely low correlations between personality variables in the four traits of interest and motor variables of locomotion, object control, and motor quotient. Although several relationships have been reported in the literature between personality traits and motor performance in adults ${ }^{13,14,15}$, we found a lack of significant relationships between these variables in our sample of 190 children. Indeed, this absence of relationships between personality traits and motor performance has also been detected in similar studies with reduced samples ${ }^{11,17}$. During childhood, the individual develops self-concept 5,6 , a process of self-recognition which is linked to personality consolidation. In this regard, we feel that our weak correlations between personality traits and gross motor performance may be due to the difficulty children have to define themselves. On account of this, we sustain that the children's responses to the PTSC may have been influenced by this limitation.

\section{CONCLUSION}

There were extremely low correlations between personality variables in the four traits of interest and the TGMD-2 motor variables of locomotion, object control, and motor quotient; hence no predictions were possible. Although the literature suggests that personality traits can influence adult motor performance, it appears that this pattern of association does not apply to children.

According to the scores in the PTSC questionnaire, our children demonstrated low levels of Psychoticism, average levels of Neuroticism, and high levels of Extroversion/Introversion and Sociability. With regard to the level of gross motor development - comprised of locomotion and object control subscales - motor quotient was 
positioned below Percentile 50 of the TGMD-2 normative rank. In addition, two-thirds of the children were classified as showing poor/very poor gross motor development.

\section{REFERENCES}

1. Gallahue DL, Donnelly FC. Developmental physical education for all children. Champaign, Human Kinetics; 2007.

2. Santos, FG, Pacheco, MM, Basso, L, Tani, G. A comparative study of the mastery of fundamental movement skills between different cultures. Motricidade. 2016;12(2), 116-126.

3. Basso L, Meira Jr CM, Oliveira JA, Forjaz CLM, Souza JA, Prista A, et al. Crescimento e desenvolvimento motor de escolares de Muzambinho: um estudo com implicações acadêmicas, sociais e de política interinstitucional. Revista Portuguesa de Ciências do Desporto. 2009;9(2-3):247-257.

4. Ulrich D. TGMD 2-Test of gross motor development examiner's manual. Austin TX: PROED. 2000;2.

5. Jung CG. O desenvolvimento da personalidade. Petrópolis, Editora Vozes Limitada; 2011.

6. Campbell, JD, Trapnell, PD, Heine, SJ, Katz, IM, Lavallee, LF, Lehman, DR. Self-concept clarity: Measurement, personality correlates, and cultural boundaries. Journal of Personality and Social Psychology. 1996;70(1):141-156.

7. Weinberg RS, Gould D. Fundamentos da psicologia do esporte e do exercício. Porto Alegre, Artmed; 2016.

8. Eysenck HJ. The biological basis of personality. London, Routledge; 2017.

9. Meira Jr CM, JFO Neiva. Efeito de traços psicológicos na aquisição de habilidades motora. 2016. In: Tani, G. (Ed.), Comportamento motor: conceitos, estudos e aplicações. Rio de Janeiro, Guanabara Koogan. Pp163-174.

10. Meira Jr CM, Fairbrother JT, Perez CR. Contextual interference and introversion/extraversion in motor learning. Perceptual and Motor Skills. 2015;121(2):447460 .

11. Meira Jr CM, Perez CR, Maia RF, Neiva JFO, Barrocal RM. Extroversão, neuroticismo e desempenho motor em crianças executando arremessos de dardo de salão. Revista Brasileira de Psicologia do Esporte. 2008;2(1):1-14.

12. Sisto FF. Escala de traços de personalidade para crianças - ETPC. São Paulo: Vetor Editora Psico-Pedagógica Ltda; 2004.

13. Stahl J, Rammsayer T. Extroversion-related differences in speed of premotor and motor processing as revealed by lateralized readiness potentials. Journal of Motor Behavior. 2008;40(2):143-54.

14. Wickett JC, Vernon PA. Replicating the movement time-extraversion link... with a little help from IQ. Personality and Individual Differences. 2000;28(2):205-215.

15. Larson GE, Saccuzzo DP. Gender, neuroticism and speed-accuracy tradeoffs on a choice reaction-time task. Personality and Individual Differences. 1986;7(6):919-921. 
Brazilian Journal of Motor Behavior

16. Beltrão NB, Meira Jr CM, Cattuzzo MT. Efeito da extroversão e da atividade física no desempenho de habilidades motoras. Revista Brasileira de Educação Física e Esporte, 2017;31(4):797-805.

17. Beltrão NB, Meira Jr CM, Souza L, Cunha A, Cattuzzo MT. Desempenho motor de crianças extrovertidas e introvertidas. Motricidade. 2012;8(S2):993-998.

18. Bassi FM, Basso L, Castro FAS, Neiva JFO, Meira Jr CM. Conhecimento sobre a presença da filmadora, níveis de ansiedade e desempenho motor global de crianças. Revista Brasileira de Educação Física e Esporte. 2017;31(4):857-867.

19. Godin GA, Shephard RJ. A simple method to assess exercise behavior in the community. Canadian Journal of Applied Sport Science. 1985;10(3):141-146.

20. Basso L, Souza CJF, Araújo UO, Bastos FH, Bianchi TT, Meira Jr CM, et al. Olhares distintos sobre a noção de estabilidade e mudança no desempenho da coordenação motora grossa. Revista Brasileira de Educação Física e Esporte. 2012;26(3):495-509.

21. Cotrim JR, Lemos AG, Néri Junior J, Barela JA. Desenvolvimento de habilidades motoras fundamentais em crianças com diferentes contextos escolares. Revista da Educação Física/UEM. 2011;22(4):523-533.

22. Nazario PF, Vieira JLL. Sport context and the motor development of children. Revista Brasileira de Cineantropometria \& Desempenho Humano. 2014;16(1):86-95.

23. Valentini NC. A influência de uma intervenção motora no desempenho motor e na percepção da competência de crianças com atrasos motores. Revista Paulista de Educação Física, São Paulo. 2002;16(1):61-75.

\section{ACKNOWLEDGEMENTS}

We thank the children who took part in the study and the data collection team. We are also grateful to Willian Peres Lemos, Januária Andrea de Souza, Elisângela Silva, and Wagner Zeferino who provided local support to enable the study in Muzambinho. We also thank Professors Jose Maia and Antonio Prista for the inspiration and support.

Citation: Meira Jr CM, Gomes AC, Gomes FRF, Santos SP, Basso L, Tani G. Personality traits and gross motor performance in children from Muzambinho/MG. BJMB.2019:13(3): 124-132.

Editor: Dr Fabio Augusto Barbieri - São Paulo State University (UNESP), Bauru, SP, Brazil; Dr José Angelo Barela São Paulo State University (UNESP), Rio Claro, SP, Brazil; Dr Natalia Madalena Rinaldi - Federal University of Espírito Santo (UFES), Vitória, ES, Brazil.

Copyright: @ 2019 Meira Jr, Gomes, Gomes, Santos, Basso and Tani and BJMB. This is an open-access article distributed under the terms of the Creative Commons Attribution-Non Commercial-No Derivatives 4.0 International License which permits unrestricted use, distribution, and reproduction in any medium, provided the original author and source are credited.

Funding: This work was sponsored by CNPq - Edital Universal 1912004 - Processo 478202/2004-0, and Edital MCT/CNPq 15/2007 - Processo 478249/2007-1.

Competing interests: The authors have declared that no competing interests exist.

DOI: https://doi.org/10.20338/bjmb.v13i4.140 